theory is correct may seem simple to resolve by accurate age determination of plants whose anatomy is well known. But Stewart ${ }^{10}$ proposed at least two lines of lycopsid evolution in the Lower Devonian, one evolving by the enation 'process' and the other according to the telome theory. Earlier, Schweitzer ${ }^{12}$ suggested several lines. A great deal of controversy revolves around plants with 'microphylls'. In the Northern Hemisphere the earliest 'microphylls' are on the Gedinnian Drepanophycus ${ }^{13}$ and 'microphylls' (with no trace of a vein) are known in Asteroxylon. Unfortunately many of the main morphological features of these plants, such as sporangia and spores, are unknown or poorly described. In the Southern Hemisphere much controversy surrounds Baragwanathia which occurs in Australia in rocks recently re-dated as Upper Silurian (Ludlow). If Baragwanathia is now correctly dated and is a true lycopsid then its presence in the Silurian may cast doubts on the origin of the lycopsids from the rhyniophytes.
With the expectation of continued discoveries by those who have already contributed to our knowledge of the early land floras and careful documentation of the geological age of their finds, the next few years promise to be as exciting as, but probably no less controversial than, the recent past.

1. Gensel, P.G. Nature 309, 785 (1984)

2. Lessuise, A. \& Fairon-Demaret, M. Ann. Soc, géol. Belg. $103,157(1980)$

3. Zimmermann, W. Palaeobotanist 1, 456 (1952)

4. Edwards, D. et al. Bot. J. Linn. Soc. 86, 19 (1983).

5. Edwards D. \& Fanning, U. Proc. R. Soc. (in the press).

6. Banks, H.P. in Evolution and Environment (ed. Drake E.T.) 73 (Yale University Press, 1968).

. Edwards, D. in The Caledonides of the British Isles Reviewed (eds Harris, A.L.., Holland, C.H. \& Leake B.E.) 405 (Geol. Soc. L.ond., 1979).

8. Gerienne, P. Ann. Soc. géol. Belg. 106, 19 (1983)

9. Banks, H.P. in Biostratigraphy of Fossil Plants (eds Dilcher, D.L. \& Taylor, T.N.) 1 (Dowden, Hutchinson \& Ross, Stroudsburg, 1980).

10. Stewart, W.N. Paleobotany and the Evolution of Plants (Cambridge University Press, 1983).

11. Bower, F.O. Primitive Land Plants (Macmillan, London, 1935).

12. Schweitzer, H.J. Bonner Paläobot. Mitteilungen 7, I

13. Schweitzer, H.J. Palaeontographica 189B, I (1983).

J. B. Richardson is at the British Museum (Natural History), London SW7 SBD.

\title{
Immunology
}

\section{The T-cell receptor completed}

\section{from Guil Winchester}

T I.YMPHOCYTES occupy a central position in the immune response. Like B lymphocytes they are capable of responding to an enormous variety of foreign antigens but they also control and coordinate the activity of other cells in the immune system. It was therefore a source of frustration and embarrassment to immunologists that the surface structure by which $T$ cells recognize antigen remained obstinately invisible for many years. Over the past eighteen months, however, a number of consistent results have gradually been building up into a picture of the $\mathrm{T}$-cell receptor. The publication of the complete sequence of the cDNAs for both subunits of a T-cell receptor on page 757 of this issue ${ }^{1}$ completes the task.

The first glimpse of the receptor came last year when monoclonal antibodies, specific for individual $\mathrm{T}$-cell clones, were found to precipitate protein dimers that seemed to be essential for the activation of $T$ cells by antigens ${ }^{2,3}$. The polypeptide subunits of the dimers have slightly different molecular weights; each polypeptide contains constant regions, which are common to several clones, and variable regions which are clone-specific ${ }^{4-6}$. The protein chemists were then overtaken by the molecular biologists. In March of this year, two groups simultaneously published the sequence of cDNA clones from both mouse ${ }^{7,8}$ and man $^{9}$ which now seem certain to code for the $\beta$-subunit of the receptor (Reinherz cited in ref.1). Since then, a genomic sequence for the $\beta$-subunit from mouse has been published ${ }^{10}$. The data show that, like the immunoglobulin gene, the $\beta$-subunit gene is split into segments in the germ line and the segments are brought together in differentiated cells to form a functional gene. Since each segment is present in a number of forms, which can be randomly assorted, the genes can encode an enormous number of receptors.

The $\alpha$-subunit has, however, remained obscure. Now Susumu Tonegawa and his colleagues have isolated and sequenced two distinct $\mathrm{CDNA}$ clones from mouse, both of which are expressed and rearranged specifically in T cells ${ }^{1}$. Their sequence identifies one as the $\beta$-subunit and the other has all the properties predicted for the $\alpha$-subunit.

The overall structure of the receptor presented by Saito et al. looks remarkably like two immunoglobulin light chains, both anchored in the membrane by a stretch of hydrophobic amino acids. Each chain has two domains on the external surface of the membrane, one constant and one variable, with the variable region at the aminoterminal end of the molecule. Between the constant domain and the cell membrane there is a short sequence which contains the cysteine that is thought to bind the two subunits together; this is followed by a sequence that spans the membrane and a short tail found in the cytoplasm. The $\alpha$-subunit (which is the larger) has a slightly longer tail which contains an extra cysteine. Saito et al. suggest that this cysteine may form 'dynamic interactions' with other molecules. One candidate would be the T3 protein which is found in all mature human $T$ cells and which seems to be involved in the triggering of $\mathrm{T}$ cells by antigen (for a review see ref.11). Removal of T3 from the surface (induced by anti-T3 antibodies) is accompanied by loss of the $\mathrm{T}$-cell antigen receptor, implying that they are physically associated.

The new data provide Saito et al. with the first opportunity to compare receptor molecules from different $T$-cell subsets. The earlier clones encoding the $\beta$-subunit were isolated from $T$-helper cells, which activate the various effector cells in the immune system, while the cDNA clones described by Saito et al. come from cytotoxic $\mathrm{T}$ cells whose primary role is the direct killing of virally infected cells.

Although only the $\beta$-subunits from different subsets can be compared, the authors draw two tentative conclusions. One is that the variable-region genes used by cytotoxic and helper cells may well come from different gene pools; the two variable-region genes compared so far are only 20 per cent similar, which is comparable to the degree of similarity between the constant-region genes of the $\beta$-subunit of the T-cell receptor and those of the immunoglobulin light chains. Since helper$T$ cells usually recognize antigen in association with class II major histocompatibility complex (MHC) products, while cytotoxic cells recognize antigen in association with class I MHC products, dissimilarity between the variable regions of helper cells and cytotoxic cells is not unexpected. Moreover, it is compatible with the observation that helper cells and cytotoxic cells have different antigen repertoires.

More surprising is the fact that the $\beta$ subunit gene from cytotoxic cells shares a constant-region sequence with one of the helper-cell genes, the identity extending over the entire $3^{\prime}$-untranslated region. Differences between the constant regions of different $T$-cell subsets might have been expected; in an immunoglobulin molecule the constant region of the heavy chain determines its functional class. Two possibilities that might account for this anomaly are discussed by Saito et al. One is simply that functional differences between the two cell types lie on the constant region of the $\alpha$-chain. The other is that the T-cell receptor is purely a recognition molecule and has a non-specific role in triggering effector functions. This question should be answered as soon as the $\alpha$-subunit from a $T$-helper cell has been sequenced. At the rate events are moving in the field that should not be long delayed.

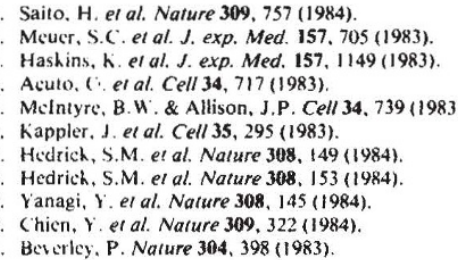

Guil Winchester was until recently an Assistant Editor of Nature. 